\title{
Peningkatan Keaktifan dan Hasil Belajar Siswa Pada Materi Debit Melalui Pendekatan Saintifik Berbantukan Media Domino Cards Bagi Siswa Kelas V SD Negeri Srumbung 2 Tahun 2019/2020
}

\author{
Euis Rosmalina \\ SD Negeri Srumbung 2, Cawakan,Srumbung, Magelang
}

\begin{abstract}
The purpose of this research is to improve learning activeness and learning outcomes of Mathematics subject on Debit material through a scientific approach assisted by Domino Cards media for the fifth grade students of SD Negeri Srumbung 2. This research is a classroom action research conducted for the reason of the low learning outcomes of discharge material proven by the pre test acquisition value. The study was conducted in two cycles, each cycle consisted of four stages, namely planning, implementing, observing, and reflecting on observations. The data were obtained in the form of observations of the activities and test values in the first cycle, and the results of observing the activities and test values in the second cycle. The results of this study showed that there was increase in student activity of $62.5 \%$ in the first cycle to $90.31 \%$ and learning outcomes that exceeded $60 \%$ completion in the first cycle to $90 \%$ in the second cycle. Theoretically and empirically, scientific approach using Domino Cards Game can increase learning activeness and learning outcomes of Mathematics subject on Debit material for the fifth grade students in SD Negeri Srumbung 2.
\end{abstract}

keywords: active learning, domino cards game, mathematics learning outcomes, scientific

\section{Pendahuluan}

Pembelajaran matematika di sekolah sangat penting, karena menjadi sarana berpikir dalam mengkaji sesuatu secara logis, dan sistematis. Matematika merupakan satu cabang ilmu pengetahuan yang diperlukan dalam keseharian (Sa'dijah, Rafiah, Gipayana, Qohar dan Anwar, 2017). Matematika harus dikuasai oleh para siswa. namun pada kenyataannya, banyak orang yang beranggapan bahwa matematika sulit dipelajari, Anggapan ini menyebabkan siswa semakin kurang termotivasi untuk belajar matematika. Dua masalah yang sering dijumpai dalam pembelajaran matematika adalah keaktifan siswa dan hasil belajar siswa yang rendah.

Penelitian ini diawali dengan hasil pre test pada tanggal 29 Juli 2019, hanya 2 siswa yang dapat mencapai $\mathrm{KKM}$ yaitu 75 dengan persentase 9.09\%. Ini dilakukan karena siswa masih kesulitan melakukan konversi satuan panjang menuju satuan volume. Siswa masih sulit memahami satuan 1 liter adalah $1 \mathrm{dm}^{3}$ atau $1000 \mathrm{~cm}^{3}, 1$ $\mathrm{cm}^{3}$ sama dengan $1 \mathrm{cc}$ dan I gram. Untuk mengatasi masalah tersebut, diperlukan pemahaman konsep yang matang, melalui strategi pembelajaran yang sesuai. Strategi Pembelajaran pada Kurikulum 2013 adalah pendekatan saintifik atau berbasis proses keilmuan yang mengembangkan kemampuan siswa mencari tahu dari berbagai sumber melalui mengamati, menanya, mencoba, mengolah, menyajikan, menyimpulkan, dan mencipta untuk semua mata pelajaran. (Sudarwan, 2013).

Karakteristik anak sekolah dasar adalah (1) Senang bermain,(2)senang bergerak,(3)senang bekerja dalam kelompok;(4)Senang melakukan secara langsung (Edward \&John, 2010). Maka dari itu diperlukan media permainan yang dapat menarik perhatian dan minat siswa untuk belajar materi debit. Media tersebut adalah permainan "Domino Cards" (kartu domino). Media domino cards digunakan untuk menumbuhkan keaktifan dan hasil belajar siswa 
meningkatkan keterampilan berhitung mencari konversi pada materi debit. Melalui permainan domino mampu merangsang pemikiran matematis siswa (John, 2015).

Berdasarkan latar belakang masalah diatas, maka rumusan masalah dalam penelitian ini adalah: Apakah melalui pendekatan saintifik berbantukan media domino cards dapat meningkatkan keaktifan dan hasil belajar siswa pada materi debit bagi siswa kelas V SD Negeri Srumbung 2 Tahun 2019/2020". Pembatasan Masalah pada penelitian ini adalah keaktifan dan hasil belajar siswa yang rendah materi debit matematika kompetensi dasar 3.3 Menjelaskan perbandingan dua besaran yang berbeda (kecepatan sebagai perbandingan jarak dengan waktu, debit sebagai perbandingan volume dan waktu). Tujuan Penelitian ini untuk meningkatkan keaktifan dan hasil belajar siswa pada materi kecepatan dan debit bagi siswa kelas V SD Negeri Srumbung 2 Tahun 2019/2020".

\section{Kajian Pustaka Keaktifan dalam Belajar}

Keaktifan siswa dalam belajar memperlihatkan bahwa siswa mengikuti pembelajaran dengan baik sehingga keaktifan belajar merupakan persoalan yang sangat penting yang tak lepas dari peran guru itu sendiri. Kegiatan pembelajaran harus dapat memberikan dan mendorong seluasluasnya keaktifan siswa. Perilaku guru untuk mendorong keaktifan siswa menurut Dimyati dan Mudjiono (2013: 62) adalah: 1) menggunakan multimetode dan multimedia; 2) memberi tugas secara individual dan kelompok; 3) memberi kesempatan pada siswa melaksanakan eksperimen dalam kelompok kecil (maksimal 3 orang); 4) memberi tugas untuk membaca bahan belajar, mencatat hal-hal yang kurang jelas; 5) mengadakan tanya jawab dan diskusi.
Contoh penjabaran di atas dapat digunakan untuk Penelitian Tindakkan Kelas (PTK) melalui permainan puzzle dengan 4 indikator keaktifan yaitu:

\section{Tabel 1 Indikator Keaktifan}

\begin{tabular}{ll}
\hline No & Keaktifan Belajar Siswa \\
\hline 1 & Bekerjasama dengan teman \\
\hline 2 & Antusias dalam permainan \\
\hline 3 & Memiliki rasa ingin tahu \\
\hline 4 & Ketepatan \\
\hline
\end{tabular}

\section{Hasil Belajar}

Hasil belajar adalah kemampuankemampuan yang dimiliki siswa setelah menerima pengalaman belajarnya (Sudjana, 2004: 22). Kemampuan pengetahuan, sikap dan keterampilan yang diperoleh siswa setelah menerima perlakuan yang diberikan oleh guru dapat mengkonstruksikan pengetahuan dalam kehidupan sehari-hari. Hasil belajar yang diharapkan adalah siswa dapat mengimplementasikan materi debit secara praktek.

\section{Pendekatan Saintifik}

Pembelajaran pada Kurikulum 2013 menggunakan pendekatan saintifik atau pendekatan berbasis proses keilmuan. Pendekatan saintifik dapat menggunakan beberapa strategi seperti pembelajaran kontekstual. Pendekatan saintifik dimaksudkan untuk memberi pemahaman kepada siswa untuk mengetahui, memahami, mempraktikkan apa yang sedang dipelajari secara ilmiah. Oleh karena itu, dalam proses pembelajaran diajarkan agar siswa mencari tahu dari berbagai sumber melalui mengamati, menanya, mencoba, mengolah, menyajikan, menyimpulkan, dan mencipta untuk semua mata pelajaran) (Sudarwan, 2013).

\section{Permainan Domino Cards}

Kata "domino" berasal dari bahasa Prancis untuk hitam dan kerundung putih yang dikenakan oleh para 
pendeta Kristen di musim dingin yang mungkin dimana nama permainan ini berasal dari Prancis. Permainan domino dapat dijumpai dimana saja namun yang paling populer yaitu di Amerika Latin. Berikut ini adalah bentuk kartu domino pada umumnya yang dikenal oleh sebagaian besar masyarakat.

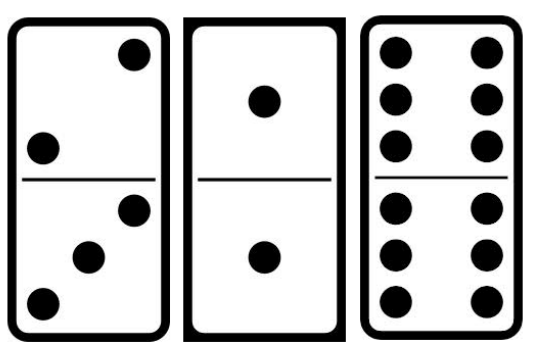

Gambar 1 Bentuk Kartu Domino di Masyarakat

Menurut Juliati (dalam Suara Managing Basic Education) dengan menggunakan kartu domino ternyata siswa lebih mudah memahami konsep materi pelajaran, siswa juga merasa senang bisa belajar melalui bermain.

Permainan domino mampu merangsang pemikiran matematis siswa (John,2015). Domino cards adalah kertas tebal berukuran kecil yang digunakan untuk bermain dimana setiap kartu dibagi menjadi dua bidang setiap bidangnya berisi 0-6 titik. Sedangkan kartu domino yang dimaksudkan disini bukanlah kartu yang digunakan oleh orang untuk berjudi melainkan kartu yang dibuat bentuknya seperti kartu domino sebagai media pembelajaran untuk menarik keaktifan belajar siswa dalam pelajaran matematika khususnya materi debit.

Kartu domino debit merupakan kertas tebal berukuran kecil yang digunakan untuk bermain dimana setiap kartu dibagi menjadi dua bagian . satu bagian di isi dengan soal dan bagian yang lainya di isi dengan konversi satuan volume/debit. Jika kartu domino biasanya berjumlah 28 , ini hanya berjumlah 12 kartu. Ukuran kartu adalah panjang $5 \mathrm{~cm}$ dan lebar $3 \mathrm{~cm}$.

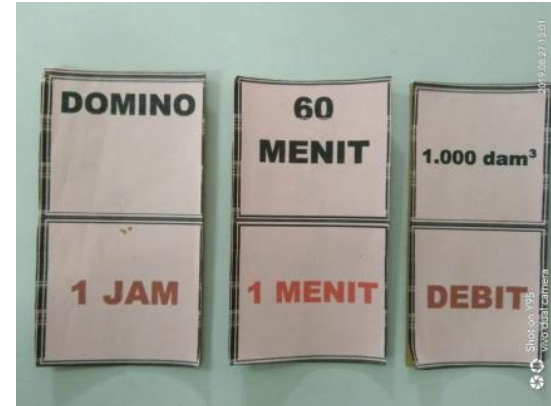

Gambar 2 Media Domino Cards

\section{Metodologi Penelitian}

Waktu pelaksanaan penelitian diadakan pada bulan Juli pada awal semester ganjil tahun pelajaran 2019/2020. Subjek dalam penelitian ini adalah siswa kelas V SD Negeri Srumbung 2, Srumbung, Magelang, yang berjumlah 20 orang yang terdiri dari 6 siswa perempuan dan 14 siswa laki-laki.

Teknik dan alat pengumpulan data pada penelitian ini menggunakan dua jenis teknik yaitu tes dan non tes. Tes yang digunakan adalah soal-soal bentuk isian 5 butir soal dan 20 pilihan ganda, untuk mengumpulkan data variabel hasil belajar siswa, Pengumpulan data nontes digunakan untuk mengumpulkan data variabel keaktifan belajar siswa, berupa hasil observasi atau pengamatan.

Analisis data dalam penelitian ini berbentuk kuantitatif. Peneliti menggunakan analisis deskriptif komparatif yaitu dengan membandingkan nilai tes antar siklus dengan nilai kondisi awal kemudian dilanjutkan refleksi brupa simpulan untuk menentukan siklus berikutnya. Indikator kinerja dalam penelitian ini untuk keaktifan yaitu $80 \%$ siswa masuk kategori aktif. Target hasil belajar siswa yaitu $80 \%$ siswa mencapai KKM.

\section{Prosedur Tindakan}

1. Rencana Tindakan

Tahap perencanaan meliputi pengumpulan informasi, sikap 
keaktifan. Pelaksanaaan pre test materi debit, yang dikaitkan dengan materi sebelumnya yaitu volume. Lalu mengidentifikasi masalah dan merancang perangkat pembelajaran dan instrumen penilaian.

\section{Pelaksanaan tindakan}

Tindakan dilaksanakan sesuai dengan langkah-langkah yang telah direncanakan.

\section{Pengamatan}

Pengamatan dilaksankan bersamaan dengan kegiatan pembelajaran.. Pengamatan keaktifan belajar dilakukan dengan mengamati kegiatan siswa selama pembelajaran berlangsung. Adapun nilai hasil belajar didapatkan dari nilai evaluasi.

4. Refleksi

Pada tahap refleksi, peneliti melakukan evaluasi terhadap pelaksanaan siklus yang telah dilaksanakan.Apabila data hasil penelitian telah sesuai dengan indikator keberhasilan, maka penelitian dilanjutkan dengan pelaporan. Sementara itu, apabila data belum sesuai dengan indikator keberhasilan, maka dilanjutkan dengan siklus berikutnya. Hipotesis dalam penelitian ini adalah melalui pendekatan saintifik berbantukan media domino cards dapat meningkatkan keaktifan dan hasil belajar pada materi debit bagi siswa kelas V SD Negeri Srumbung 2 tahun ajaran 2019/2020.

\section{Hasil Tindakan}

\section{Deskripsi Kondisi Awal}

Pada kondisi awal keaktifan belajar yang berlangsung selama pembelajaran hanya beberapa siswa yang aktif mendengarkan penjelasan guru dan bertanya sedang sebagian besar siswa pasif . Hasil belajar belum maksimal, terbukti masih rendahnya hasil belajar secara umum, demikian pula untuk muatan pelajaran matematika, pada pretest materi debit
20 soal PG yang dilaksanakan pada tanggal 29 Juli 2019 , dari 20 siswa hanya 2 orang yang mencapai KKM, hasil yang diperoleh adalah $9.09 \%$ mencapai KKM sedangkan 81,82 \% tidak tuntas

Tabel 2 Kondisi Hasil Belajar Awal

\begin{tabular}{llll}
\hline Nilai & Jumlah & Prosentase & Kategori \\
\hline $0-33$ & 7 & 35 & $\begin{array}{l}\text { Amat } \\
\text { kurang }\end{array}$ \\
\hline $34-74$ & 11 & 55 & Kurang \\
\hline $75-83$ & 1 & 5 & Cukup \\
\hline $84-91$ & 0 & 0 & Baik \\
\hline $92-100$ & 1 & 5 & $\begin{array}{l}\text { Amat } \\
\text { Baik }\end{array}$ \\
\hline $\begin{array}{l}\text { Jml } \\
\text { Peserta }\end{array}$ & 20 & 100 & \\
\hline
\end{tabular}

\section{Deskripsi Siklus I}

1. Perencanaan Tidakan pada siklus 1 berdasarkan hasil pretest menunjukkan perlunya tindakan kelas unrtuk memperbaiki hasil belajar secara aktif melalui pendekatan saintifik berbantukan media domino cards. Rencana pembelajaran terdiri dari kegiatan pendahuluan, inti, dan penutup.

2. Pelaksanaan tindakan siklus 1 dilaksanakan pada tanggal 28 dan 30 Juli 2019. Hari ke-1 diawali dengan penyampaian materi satuan volume dengan syair lagu "Bintang Kecil", pembelajaran berlangsung dengan pendekatan saintifik.

3. Cara Permainan

a. Guru menyampaikan rancangan pembelajaran yang akan digunakan.

b. Guru membuat kelompok yang terdiri dari 2-4 siswa Kemudian tiap siswa dalam kelom pok tersebut menempati tempat saling berhadapan. Guru membagikan kartu domino kepada setiap kelompok sebanyak 12 kartu sesuai dengan satuan yang dipelajari.

c. Permainan dimulai dengan kartu pertama bertuliskan domino. 
d. Peserta secara bergiliran mencari pasangan konversi volume/debit.

e. Peserta diberi kesempatan sampai 5 hitungan untuk mencari kartu yang tepat.

f. Apabila tidak bisa mencari jawaban konversi yang benar, maka peserta tersebut mendapatkan 1 kesalahan.

g. Dilanjutkan oleh peserta lain, sampai kartu terpasang semua dengan ditutup kartu finish.

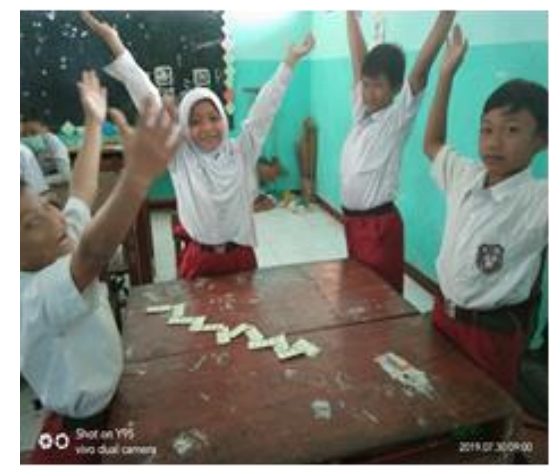

Gambar 2 Pembelajaran Saintifik Dengan Media Domino Cards

\section{Data Pengamatan}

Pada tablel keaktifan siswa siklus pertama hanya beberapa siswa yang dominan di setiap kelompok, kelompok 1 menyelesaikan permainan paling cepat, namun hanya satu anak yang mengerjakan, begitu pula kelompok yang lain. Kelompok 2 adalah kelompok yang terakhir menyelesaikan permainan, karena mengalami kesulitan dalam mengkonversi debit. Kelompok 4 dapat menyelesaikan permainan setelah mendapat bimbingan dsari guru. Capaian keaktifan siswa hanya $62.5 \%$ berdasarkan data hasil belajar, siswa yang mendapat nilai 75 keatas sebanyak 13 orang. Pada siklus I sudah mengalami peningkatan yaitu dari rata-rata 45.10 menjadi 74.85. Besar peningkatan $29.8 \%$ dan prosentase ketuntasan 65\%. Ini menunjukkan belum mencapai hasil yang diharapkan.
5. Hasil refleksi

Berdasarkan analisis pengamatan keaktifan dan hasil belajar siswa, diketahui bahwa pada sikius I indikator keberhasilan belum tercapai sehingga perlu diadakan tindakan perbaikan pada siklus II agar hasil belajar siswa dapat ditingkatkan. Perbaikan tersebut diawal dengan tayangan video materi debit untuk meningkatkan pemahaman siswa lebih mendalam, adanya tutor sebaya di setiap kelompok dan permainan domino hanya dikerjakan oleh kelompok kecil saja, terdiri dari 2 orang.

\section{Deskripsi Siklus II}

1. Perencanaan tindakan terdiri dari kegiatan: pendahuluan, inti, penutup. Siswa dibagi menjadi 10 kelompok kecil terdiri dari 2 siswa.

2. Pelaksanaan tindakan dilaksanakan pada tanggal 6-7 Agustus 2019 dengan menggunakan media domino cards secara berkelompok kecil pada materi debit hal 49 kegiatan 8 .

a. Mengamati video pembelajaran materi debit https://www.youtube.com/watc $\underline{h} ? \mathrm{v}=u q K 7 p 4 I-W Q Q \& \mathrm{t}=318 \mathrm{~s}$

b. Guru bertanya berkaitan materi yang berhubungan dengan aliran, volume, kecepatan, untuk merangsang keinginantahuan siswa.

c. Siswa berlatih soal-soal debit secara mandiri pada buku siswa hal.70.

d. Siswa saling mengoreksi.

e. Siswa dibagi menjadi 10 kelompok yang terdiri dari 2 orang.

3. Data pengamatan pada siklus II. Keaktifan siswa meningkat menjadi $89,7 \%$. Keaktifan ini tampak ketika siswa ingin terus mencoba permainan domino cards, hanya 3 orang yang tidak bisa menyelesaikan dengan tepat. Berdasarkan data hasil belajar, siswa yang mendapat nilai 75 
keatas sebanyak 18 orang. Pada siklus II sudah mengalami peningkatan yaitu dari rata-rata 74.85 menjadi 82.25 dan prosentase ketuntasan 90\%. Ini menunjukkan sudah mencapai hasil yang diharapkan.

4. Hasil refleksi. Berdasarkan analisis hasil pengamatan pada sikius II terjadi peningkatan baik keaktifan maupun hasil belajar siswa, walau belum mencapai ketuntasan 100\% dari keseluruhan siswa.

Hasil pengamatan keaktifan dan hasil belajar

Tabel 3 Keaktifan Belajar

\begin{tabular}{|c|c|c|c|c|c|c|c|}
\hline \multirow[b]{2}{*}{ No } & \multirow[b]{2}{*}{ Aspek yang diamati } & \multicolumn{3}{|c|}{ Siklus I } & \multicolumn{3}{|c|}{ Siklus II } \\
\hline & & Rata-rata & Persentase & Kriteria & $\begin{array}{l}\text { Rata- } \\
\text { rata }\end{array}$ & Persentase & Kriteria \\
\hline 1 & $\begin{array}{l}\text { Bekerjasama dengan } \\
\text { teman }\end{array}$ & 2.9 & 72.5 & CA & 3.65 & 91.25 & SA \\
\hline 2 & $\begin{array}{l}\text { Antusias dalam } \\
\text { permainan }\end{array}$ & 2.5 & 62.5 & CA & 3.75 & 93.73 & SA \\
\hline 3 & $\begin{array}{l}\text { Memiliki rasa ingin } \\
\text { tahu }\end{array}$ & 2.6 & 63.75 & CA & 3.75 & 93.75 & SA \\
\hline \multirow[t]{3}{*}{4} & Ketepatan & 2.05 & 51.25 & $\mathrm{KA}$ & 3.3 & 82.5 & A \\
\hline & & 2.5 & 62.5 & & 3.6 & 90.31 & \\
\hline & Kriteria & & & $\mathrm{CA}$ & & & Aktif \\
\hline
\end{tabular}

Hasil Pengamatan Hasil Belajar siswa

Tabel 4 Nilai Tes

\begin{tabular}{rllrrrrr}
\hline \multirow{2}{*}{ No } & $\begin{array}{c}\text { Hasil } \\
\text { Belajar }\end{array}$ & Kategori & \multicolumn{2}{l}{ Siklus I } & \multicolumn{2}{l}{ Siklus II } \\
\cline { 3 - 7 } & & Frekuensi & Persentase & Frekuensi & Persentase \\
\hline 1 & $0-33$ & Amat & & & & & \\
\hline 2 & $34-74$ & Kurang & 7 & 35 & 2 & 10 \\
\hline 3 & $75-84$ & Cukup & 5 & 25 & 10 & 50 \\
\hline 4 & $84-91$ & Baik & 3 & 15 & 6 & 30 \\
\hline 5 & $92-100$ & Amat baik & 5 & 25 & 2 & 10 \\
\hline & Jumlah & & 20 & 100 & 20 & 100 \\
\hline
\end{tabular}

Dari tabel diatas tampak peningkatan persentase siswa yang tuntas. Untuk lebih jelasnya disajikan grafik berikut.

Diagram Peningkatan Keaktifan dan Hasil Belajar

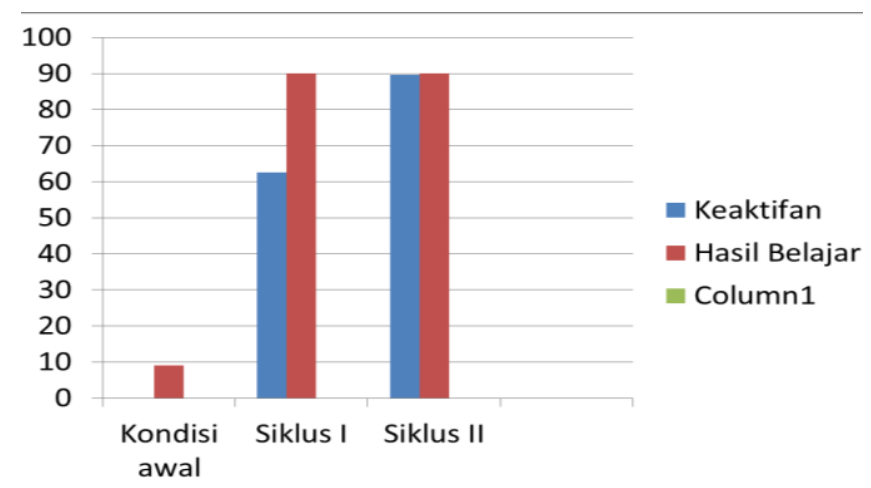




\section{Penutup}

\section{Simpulan}

Berdasarkan hasil penelitian dan pembahasan yang telah dilakukan peneliti maka dapat disimpulkan: melalui pendekatan saintifik berbantukan media domino cards pada materi debit dapat meningkatkan keaktifan dan hasil belajar siswa kelas V SD Negeri Srumbung 2 tahun ajaran $2019 / 2020$.

\section{Saran}

\section{Bagi Sekolah}

Sekolah dapat memberikan kebijakan kepada para guru untuk kreatif dan inovatif dalam menerapkan media sederhana dan membuat pembelajaran lebih menarik, karena dengan media berupa domino cards dapat meningkatkan keaktifan dan hasil belajar siswa.

\section{Bagi Guru}

Media pembelajaran permainan domino cards ini bisa digunakan untuk menumbuhkan keaktifan dan hasil belajar siswa lebih meningkat. Alangkah baiknya penanaman konsep juga dilaksanakan melalui tutor sebaya.

\section{Bagi Siswa}

Siswa hendaknya aktif dalam proses pembelajaran agar dapat memahaminya. Selain itu agar proses pembelajaran dapat terlaksana dengan baik diharapkan siswa tidak ramai di dalam kelas ataupun sibuk dengan temannya, sebaiknya siswa berperan aktif dalam proses pembelajaran.

\section{Peneliti}

Peneliti dapat menerapkan media permainan domino cards pada pelajaran matematika dan pada muatan pelajaran yang lain sehingga keaktifan dan hasil belajar siswa dapat meningkat.

\section{Daftar Pustaka}

Arikunto, Suharsimi. 2006. Penelitian Tindakan Kelas. Jakarta: PT Bumi Aksara Anwar, S. 2005. Evaluasi Pembelajaran dan Program Pendidikannya. Yogyakarta: Pustaka Pelajar

Daryanto dan Muljo Rahardjo. 2012. Media Inovatif. Yogyakarta: Gava Media Hamalik, Oemar. 2011. Proses Belajar Mengajar. Jakarta: PT Bumi Aksara Hamzah, 2007. Perencanaan Pembelajaran. Jakarta: Bumi Aksara.

Masidjo. 2010. Penilaian Pencapaian Hasil Belajar Siswa di Sekolah. Yogyakarta: Kanisius

Slameto. Belajar dan Faktor-faktor yang Mempengaruhinya. Cet. II; Jakarta: Rineka Cipta. 1995.

Utami Munandar. 1992. Mengembangkan Bakat dan Keaktifan Anak Sekolah: Petunjuk Bagi Para Guru dan Orang tua. Jakarta: PT Gramedia Widiasaran.

Yantias, Susi Budi Utami Yuli. 2009. Pengembangan Strategi Domino dalam Pembelajaran Menulis Cerpen Kelas X SMA Islam Malang. Skripsi pada Jurusan Sastra Indonesia-Fakultas Sastra UM: tidak diterbitkan.

http://en.wikipedia.org/wiki/Domino (diakses 5 Agustus 2012)

Ismail, Adang. 2006. Education Games. Yogyakarta: Pilar Media 